\title{
VIDEOGAME, ESCOLA E CONTO POPULAR
}

\section{Videogame obedece à tradicional estrutura do conto popular e, embora pausterizado culturalmente, serve para repensar o discurso pedagógico}

O atual desenvolvimento da informática e a aplicação dessa tecnologia nos mais variados bens de consumo motivou, subitamente, uma corrida às lojas de eletroeletrônicos, em busca da satisfação dos desejos provocados por novos equipamentos. Assim, uma geração que até bem pouco tempo se deslumbrava diante dos coloridos astros de TV, viu-se diante de inúmeros botões, luzes e sons tão atraentes quanto enigmáti$\cos$. E, naturalmente, orgulhou-se com a habilidade demonstrada por suas crianças ao manipular, com tanta facilidade, a moderna parafernália eletrônica. Esse fator pode caracterizar-se como determinante na rápida difusão de um novo tipo de brinquedo, o videogame, ' em detrimento de jogos clássicos como o tabuleiro, as bicicletas, carri-

\section{O AUTOR}

Luciano Biagio Toriello

Professor de Português da Escola Estadual de Primeiro Grau Jardim Santa Ângela, Cotia, em São Paulo. Pesquisador no Projeto A circulação de textos na escola. E-mail toriello@usp.br nhos, bonecas etc. Para entender esse novo universo lúdico e desvendar um pouco de seus mistérios, tive a necessidade de praticar por muitas horas os jogos de maior preferência entre as crianças, evitando qualquer tipo de preconceito em relação à novidade dos jogos eletrônicos. Dessa forma. foi possível perceber um pouco melhor algumas das estruturas presentes na elaboração dos games.

\section{OS EQUIPAMENTOS DISPONÍVEIS E OS DIVERSOS JOGOS}

Duas empresas multinacionais de origem japonesa, a Nintendo e a SEGA, disputam mundialmente o crescente mercado consumidor de jogos eletrônicos. No Brasil, elas são representadas pela Playtronic e Tec-Toy, respectivamente, com os consoles ${ }^{2}$ Supernintendo e Mega Drive, aparelhos que sintetizam avançados recursos de informática com os divertidos jogos que já chamavam a atenção na década de 70 , conhecidos como fliperamas ou árcades. Também são oferecidos acessórios, como: pistolas;

1. Este texto está apoiado nos dados da pesquisa Aprender e ensinar com textos na escola, coordenada pelo Prof. Dr. Adilson Odair Citelli, e realizada no âmbito do Projeto Integrado A circulação de textos na escola, coordenado pela Prof Dr Lígia Chiappini Moraes Leite. Serviu-nos como referência inicial o ensaio de José Luís Miranda, Jogos Interativos e Cotidiano Escolar, publicado no livro Ensinar e aprender com textos não-escolares. São Paulo: Cortez, v. 3, I997; coordenado pelo Prof. Dr. Adílson Odair Citelli.

2. Como são chamados os aparelhos domésticos que permitem a leitura dos cartuchos com diferentes tipos de jogos. 
mouses; cabos para maior número de jogadores; sistema de leitura de $C D-\mathbf{R O M}^{3}$; conexão telefônica a dados bancários, permitindo aos pais o controle de suas finanças ${ }^{4} \mathrm{e}$ acesso à rede de computadores Internet. ${ }^{5}$

Outra característica comum entre as duas rivais é a presença de um mascote exclusivo de cada companhia, funcionando como um personagem-logotipo facilmente identificado pelas crianças. $\mathrm{O}$ astro da Nintendo chama-se Mário Bross, um homenzinho barrigudo e bigodudo; o concorrente da SEGA é um porco-espinho conhecido como Sonic, um bichinho azul com olhos expressivos, pés imensos e incrível velocidade. A semelhança entre os dois sistemas e o grande número de jogos equivalentes para os dois aparelhos faz da escolha entre um ou outro uma questão quase subjetiva.

\section{Roteiro estruturado:}

\section{sempre a luta do bem contra o mal}

Os jogos podem ser classificados de acordo com uma característica de maior domínio em cada título, há os de luta, de aventura, tiro, esporte, simuladores, RPG (Rolling Playing Game) e raciocínio. Os jogos de luta são os de maior sucesso entre a garotada. Neles, um aglomerado de personagens/lutadores, representantes das mais diferentes artes marciais, enfrentam-se em um ringue em que não há regras e muito menos compaixão. $\mathrm{A}$ popularidade dos títulos dessa categoria é diretamente equivalente ao nível de violência das cenas desses jogos, com cabeças decaptadas, corações arrancados, corpos dilacera- dos e muitas poças e jatos de sangue. As aventuras possuem um roteiro razoavelmente elaborado, trazendo sempre a eterna luta do bem contra o mal, com personagens estereotipadas e clichês já consagrados na literatura popular, como veremos adiante em maiores detalhes. O desafio é fazer a personagem vencer obstáculos, conquistar novos poderes, derrotar vilões e sair ileso para atingir um determinado objetivo.

Os jogos de tiro caracterizam-se pela exigência de rápidos reflexos em relação às cenas apresentadas. Pode-se invadir um planeta com uma pequena espaçonave ou eliminar típicos bandidos do velho Oeste americano. A prática de diversas modalidades esportivas como - tênis, futebol, basquete entre outros - pode ser feita com alta competência e nenhuma gota de suor. Através de uma perspectiva muito parecida com as transmissões realizadas pela TV, o jogador pode controlar os movimentos dos atletas eletrônicos e, até, substituí-los quando apresentarem indícios de fadiga. Nos simuladores é possível ter a ilusão de controlar facilmente aparelhos sofisticados como aviões, helicópteros, carros de corrida, motocicletas e até naves espaciais, muitas vezes com um surpreendente realismo.

Os Rolling Playing Games são adaptações dos Jogos de Representação para a linguagem do videogame, porém, nessa versão, falta o principal ingrediente do original, a imaginação. Os jogos de raciocínio são quebra-cabeças que exigem uma rápida capacidade em organizar elementos seguindo critérios lógicos.

\footnotetext{
3. Sistema de gravação de dados digitais decodificados por leitura ótica (laser). Devido à sua capacidade de acumular um grande número de informações, permite o desenvolvimento de jogos com gráficos de maior resolução e alta fidelidade de som. Esse acessório é disponível para o Mega Drive, com a denominação de SEGA CD.

4. O Bradesco, em conjunto com a representante da SEGA no Brasil, a Tec-Toy, lançou recentemente no mercado um cartucho que permite aos usuários o acesso ao seu banco de dados, bastando conectar o console Mega Drive com uma linha telefônica.

5. É oferecido para o Mega Drive um cartucho capaz de acessar os dados da Internet, devendo o usuário pagar uma taxa mensal à Tec-Toy, de acordo com o tempo de uso.
} 


\section{OS JOGOS DE AVENTURA E SUA ESTRUTURA}

De acordo com a descrição anterior, a experiência de enfrentar os jogos eletrônicos pode parecer, em um primeiro momento, pouco estimulante. No entanto, quando o jogador assume o desafio, ultrapassando diferentes estágios impostos pela máquina, é quase impossível evitar uma virtual sensação de superioridade, raramente alcançada em uma realidade em que há mais vencidos do que vencedores.

Esse prazer da fantasia não é uma experiência exclusiva das crianças de hoje: quando os computadores só existiam nas aventuras de Flash Gordon e a tecnologia era uma possibilidade nos livros de Júlio Verne, muitas crianças sentiram-se igualmente motivadas diante das aventuras de Zorro, Ulysses, El Cid, O Príncipe Valente e tantos outros.

Comparando, sob esse aspecto, os modernos jogos de aventura com a leitura dos tradicionais heróis, é impossível deixar de perceber uma relação muito estreita entre ambos. Evitando, neste momento, questionar as possíveis diferenças qualitativas no plano da enunciação, pode-se destacar a equivalência estrutural existente no enunciado das duas manifestações. Para aclarar esta afirmativa, vamos nos valer do trabalho desenvolvido pelo teórico russo V. I. Propp $^{6}$, que nos anos vinte procurou constituir uma morfologia dos contos populares. Faremos algumas observações sobre o método de Propp, para a melhor compreesão do que será dito em seguida sobre a estrutura dos games.

\section{A morfologia do conto maravilhoso}

Estudioso do folclore russo, Propp passou a se preocupar em reunir uma coletânea de contos populares e classificá-los de acordo com suas temáticas principais. Esse trabalho pode parecer, de antemão, relativamente fácil, porém, ao manipular os diversos tipos de contos encontrados, Propp colocou a questão fundamental: "como classificar de forma eficiente as variadas narrativas populares?". Estudando as tentativas de outros teóricos, ele pôde perceber que nenhuma das classificações anteriormente feitas conseguiam total eficiência porque sempre havia contos em condições de receber, pelo menos, duas classificações diferentes. Vejamos um exemplo: Joãozinho e Maria, conto bem popular no Ocidente, poderia ser classificado como um Conto de feitiçaria puro e, ao mesmo tempo, como uma Fábula moral (classificação de Wundt em Psicologia dos povos). Após várias tentativas e percebendo que a maioria dos contos possuía correspondentes muito semelhantes, diferenciando-se apenas pelas particularidades de cada cultura, Propp concluiu que o melhor método de classificação seria a identificação das partes mínimas de significação dos contos, ou seja, a sua morfologia. Cada parte mínima do conto foi determinada pela função exercida por uma personagem qualquer de um conto. Vejamos:

a) "O príncipe recebeu o cavalo alado das mãos do velho mendigo para alcançar o reino dos ventos".

b) "Encantada pelo duende, a garça gigante levou o destemido para a Terra Azul".

Apesar de serem partes de diferentes contos, a função é exatamente igual, ou seja, o 
meio mágico passa às mãos do herói. Isolando as funções de um número limitado de contos maravilhosos russos, observando a ordem cronológica de cada uma e identificando-as com diferentes símbolos, Propp elabora um sistema metodológico capaz de codificar qualquer conto popular. Assim uma combinação de diferentes símbolos representa a estrutura de cada conto. Vejamos:

$$
\alpha \mathrm{A}^{1} \mathrm{~B}^{2} \mathrm{C} \uparrow \mathrm{H}^{2} \mathrm{~J}^{1} \mathrm{~K}^{1} \downarrow \mathrm{W}^{3}
$$

Nesse momento, diante de tão esquisita fórmula, qualquer um pensa em fugir do texto, identificando-a como um enigma elaborado por algum cientista maluco, na forma mais estereotipada do termo. $\mathrm{Na}$ verdade, é uma representação simbólica de uma estrutura típica de conto popular, como podemos constatar na descrição adiante, na qual temos uma das possibilidades proposta por Propp:

$\alpha$ Situação inicial;

A ${ }^{\prime}$ Dano - rapto de um ser humano;

B² Mediação - envio do herói;

C Início da reação;

$\uparrow \quad$ Partida do herói;

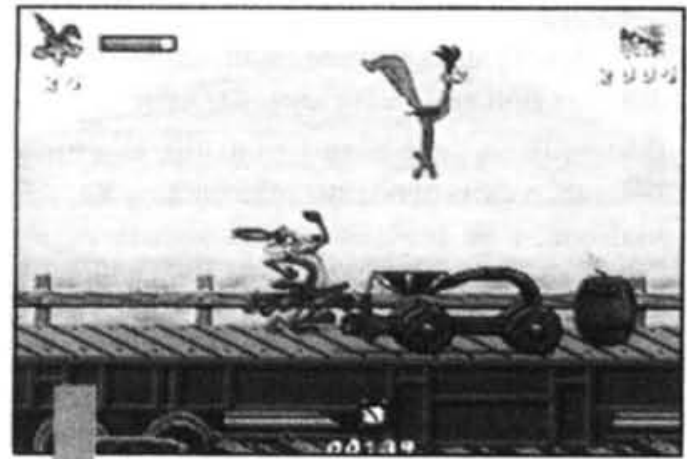

Seri que Papaléquas cai nas armadithas do Coiote?
$\mathrm{H}^{\mathrm{I}}$ Luta contra o malfeitor em campo aberto;

J1 O herói vence o combate;

K A vítima é libertada após a ação do herói;

$\downarrow$ Regresso do herói;

$\mathrm{W}^{3} \mathrm{O}$ herói recebe retribuição em dinheiro.

Observando a descrição simplificada de cada símbolo, é possível entender a universalidade das funções descritas por Propp. Afinal, não é difícil imaginar uma narrativa qualquer que obedeça, rigorosamente, à ordem exposta acima ou, pelo menos, identificar alguma função presente em uma história qualquer. Naturalmente, não é o objetivo desse trabalho transcrever todas as funções descritas pelo teórico e, muito menos, esgotar as informações contidas no seu método: deseja-se apenas oferecer uma breve noção. possibilitando o acompanhamento das análises à frente.

\section{A estrutura dos games de aventura}

Apresenta-se, a seguir, um breve resumo de um fio narrativo extraído de três jogos de ação e, depois, sua demonstração estrutural segundo a metodologia adotada por Propp.

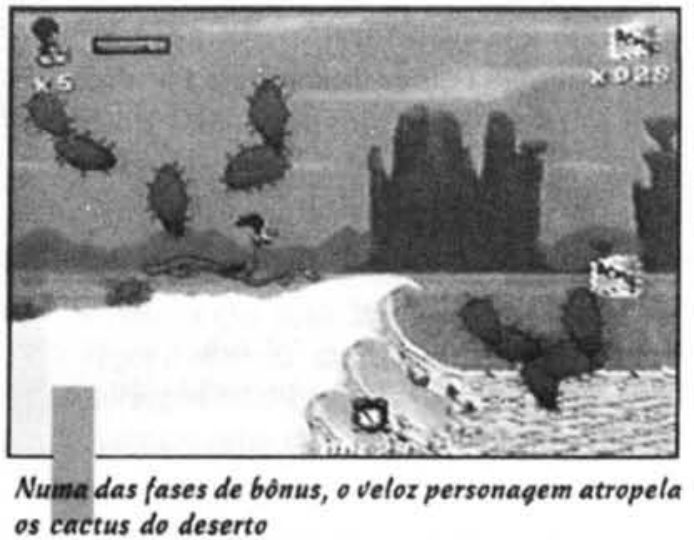




\section{a) Sonic - O Porco-espinho (SEGA - Me-} ga Drive): É um simpático personagem com grandes e expressivos olhos, um corpo aerodinâmico e imensos sapatos. Sua missão é libertar todos os animais da floresta que foram aprisionados e transformados em robôs pelo terrível Dr. Robotnik. Para alcançar seu objetivo, o personagem conta com sua velocidade supersônica (sugerida pelo seu nome), magias especiais contidas em aparelhos de TV espalhados pelo caminho, que podem lhe proporcionar diferentes habilidades e, ainda, anéis que, colhidos pelo caminho em grande quantidade, podem aumentar o número de vidas extras e a pontuação do placar. Chegando ao final de cada estágio, o herói luta diretamente contra o malfeitor armado com algum tipo de suas invenções. Após enfrentar inúmeros estágios que apresentam diferentes dificuldades, o herói enfrenta seu oponente numa última batalha, vence e liberta todos os animais da transformação provocada pelo Dr. Robotnik.

\section{Estrutura:}

$\alpha \quad$ Situação inicial - os animais na floresta, livres de qualquer ameaça;

A 11 Dano por enfeitiçamento ou transformação - os animais são transformados em perversas máquinas;

C Início da reação;

$\uparrow \quad$ Partida do herói;

F5 Posse de um meio mágico que é achado - Os itens que aumentam o poder de Sonic e os anéis que são achados pelo caminho;

$\mathrm{H}^{1}$ Luta contra o malfeitor em um combate em campo aberto - Sonic deve enfrentar o Dr. Robotnik que está sempre armado com uma eficiente máquina de guerra, além de escapar dos perigos do próprio campo de luta, como jatos de lava, pontes desmoronando etc.;

J1 Vitória sobre o agressor em combate Sonic derrota o Dr. Robotnik;

$\mathrm{K}^{8}$ Reparação do dano ou da carência com quebra do sortilégio, do enfeitiçamento - Ao derrotar o Dr. Robotnik todos os animais voltam ao estado normal;

$\downarrow \quad$ Regresso do herói - Todos os animais voltam para a floresta e voltam a viver felizes.

\section{b) Mário Bross (Nintendo - Superninten-} do): Um simples encanador, baixinho e barrigudo, deve salvar uma princesa presa nas muralhas da fortaleza do dragão Goopa. Para alcançar o castelo, deve atravessar um mundo mágico e enfrentar inimigos como tartarugas, morcegos, fantasmas, aves e outros seres estranhos. Para auxiliar a aventura, surgem de vez em quando uns cogumelos que podem dar poderes especiais ao personagem. Um outro auxiliar é Yoshi, um engraçado filhote de dinossauro que, além de servir como montaria, come alguns bichos enviados para impedir o sucesso do herói. Após a derrota do dragão, Mário recebe um singelo beijo de agradecimento de sua princesa.

\section{Estrutura:}

$\alpha \quad$ Situação inicial - Todos vivendo felizes;

$\mathrm{A}^{1}$ Dano com o rapto de um ser humano A princesa é raptada por Goopa;

$\mathrm{A}^{15}$ Dano com aprisionamento - A princesa é mantida prisioneira;

C Início da reação;

$\uparrow$ Partida do herói;

$F^{7}$ Posse de um objeto mágico comido ou bebido - Ao encostar no cogumelo o herói adquire o poder mágico; 
f9 O auxiliar mágico coloca-se à disposição do herói sem fórmula de apelo - $\mathrm{O}$ dinossauro Yoshi ajuda Mário, comendo os inimigos;

$\mathrm{G}^{2} \quad$ Viagem ao lugar de destinação a cavalo ou carregado - Apesar de não ser em todo momento, Mário viaja carregado pelo dinossauro;

$\mathrm{H}^{1}$ Luta contra o malfeitor num combate em campo aberto - Mário luta com o dragão Goopa;

J1 Vitória sobre o agressor em combate Mário vence Goopa;

$\mathrm{K}^{10}$ Reparação do dano ou da carência com libertação - A princesa é libertada;

N Realização da tarefa - Mário tem sucesso na sua aventura:

Q Reconhecimento do herói - A princesa agradece Mário por sua valentia com um pueril beijo.

\section{c) Space Ace (SEGA - Mega Drive com} SEGA CD): A ação se desenrola com três personagens principais - um herói de frágil aparência adolescente (sardento, magricela e desengonçado), uma jovem atraente e delicada, um vilão gigante e temível; tudo

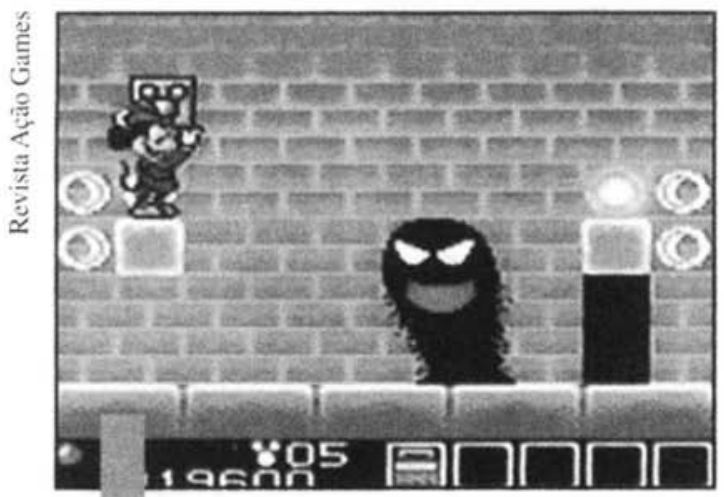

Mickey prepara-se para detonar um inimigo. 0 mes. mo estilão do "pega-e-joga" de seus outros games num cenário espacial com monstros mutantes, espaçonaves, robôs, armas laser, asteróides e lavas vulcânicas.

O casal de namorados sofre um ataque de estranhos raios vindos de um asteróide metálico comandado pelo tirano. Um deles aprisiona a garota, levando-a para seu interior, enquanto outros tentam atingir fulminantemente o jovem herói. Para salvar sua amiga das garras do agressor que pretende tê-la como noiva, o herói conta apenas com uma arma laser, sua espaçonave e uma espécie de magia vinda de seu relógio de pulso que, nos momentos de maior dificuldade, o transforma num super-herói com toda a carga de estereótipos físicos característicos dos filmes de ação: um tórax extremamente volumoso em contraste com uma fina cintura, braços musculosos, topete no cabelo, queixo saliente com covinha, um timbre de voz grave e sedutor, além de uma aguçada inteligência.

Após pilotar sua nave por estreitos labirintos, escapar de monstros devoradores, derrotar um gigante, destruir robôs imensos, dirigir uma motocicleta potente por vielas repletas de ferozes animais mutantes e mergulhar em um mar repleto de famintos tubarões cibernéticos, finalmente o he-

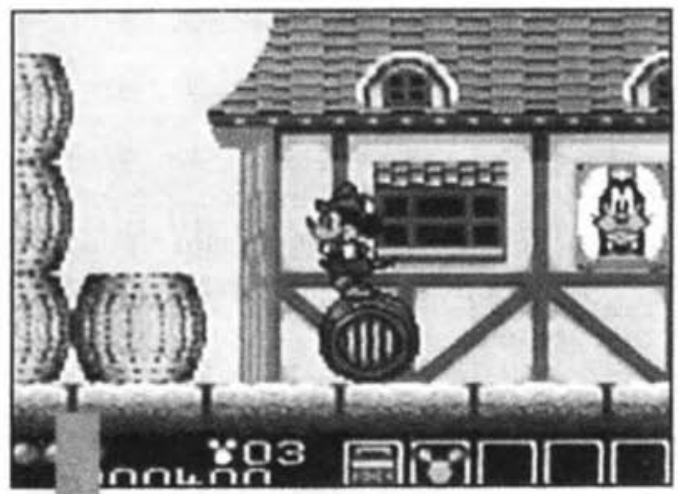

o Pateta não participa do game, mas sua carinha pinta em algumas telas 
rói deve enfrentar o inimigo em uma luta corpo a corpo e, ainda, salvar sua namorada que, pendurada por uma corda, desce lentamente para um poço cheio de lava incandescente.

Mas, antes do romântico encontro final, o malfeitor ainda possui forças para lançar contra o casal um último tiro vindo de um canhão laser. Habilmente, o mocinho, agora com a definitiva aparência bela e forte, protege a garota enquanto aponta contra o canhão inimigo um espelho que reflete com a mesma intensidade o tiro sofrido. Atingido pelo seu próprio veneno, o colossal vilão vai encolhendo até transformar-se em um adorável bebê, logo acolhido carinhosamente nos braços da jovem.

\section{Estrutura:}

$\alpha \quad$ Situação inicial: $\mathrm{O}$ casal de namorados antes do ataque;

A 1 Rapto de um ser humano, a garota é raptada através de um raio trator;

$\mathrm{A}^{15}$ Aprisionamento: a garota é mantida presa;

$\mathrm{A}^{16}$ Ameaça de matrimônio forçado: o objetivo do vilão é casar com a garota;

C Início da reação;

$\uparrow \quad$ Partida do herói: o jovem parte para resgatar sua garota;

$\mathrm{F}^{6}$ Posse de um objeto mágico que aparece espontaneamente: o herói possui o relógio que faz aumentar sua força física, no jogo ele já possui o objeto desde o início e o equipamento só funciona espontaneamente nos momentos mais críticos:

$\mathrm{G}^{1} \quad$ Viagem ao seu destino por vôo: o herói alcança o asteróide pilotando sua espaçonave;
$\mathrm{H}^{\mathrm{I}}$ Luta contra o malfeitor em um combate em campo aberto: o herói enfrenta o vilão em uma luta corpo a corpo;

J1 Vitória sobre o agressor em combate: o herói vence o vilão em força física e em inteligência;

$\mathrm{T}^{1}$ Transfiguração com nova aparência física - $\mathrm{O}$ rapaz assume a imagem bela $\mathrm{e}$ poderosa definitivamente;

U Castigo do agressor: $\mathrm{O}$ agressor é transformado em um bebê;

$\mathrm{W}^{1}$ Noivado, compromisso: como recompensa o herói recebe o compromisso de casamento sugerido pela presença do bebê acolhido nos braços da jovem.

Como se pode verificar, as estruturas funcionais das narrativas, com maior ou menor grau de elaboração, possuem pequenas diferenças na ação, mantendo uma estrutura básica entre elas, ou seja, o herói luta para atingir um objetivo, atravessando obstáculos, auxiliado por elementos mágicos, até enfrentar o agressor e derrotá-lo em um combate para, em seguida, ser reconhecido como herói e homenageado de alguma forma. Referências às passagens conhecidas dos contos populares não faltam, como o herói espacial derrotando seu oponente com a mesma arma tecnológica que petrifica Medusa ou a semelhança entre os amigos do Sonic transformados em robôs pelo Dr. Robotnik e a tripulação de Ulysses transformada em porcos pela bruxa Circe.

A diferença fundamental entre $o$ antigo e o novo reside apenas em uma forma de interatividade do leitor eletrônico com o mundo da fantasia, talvez em detrimento da imaginação. 
Essa interação oferecida ao jogador é direcionada, ou seja, ele é obrigado a movimentar a figura com ações específicas como pular, agachar, agarrar um objeto ou golpear um oponente, sendo punido imediatamente com a eliminação de seu personagem se não corresponder exatamente às exigências impostas pelo jogo. Após perder todas as vidas disponíveis do boneco, o jogador deve reiniciar a partida e refazer todos os passos dados até descobrir a forma de movimentação necessária para ultrapassar o estágio. Essa constante repetição de movimentos ao passar pelas fases anteriormente vencidas tornam-se automáticas, só motivadas pelo forte desejo de desvendar a nova fase, com diferentes gráficos e maior nível de dificuldade. Essa fórmula de sedução para manter o interesse na partida também é muito semelhante à técnica do bom contador de histórias, amarrando sempre o início de uma outra ao término de sua narrativa, como Sherazade mantendo sua vida por mil e uma noites.

Buscando atingir um maior público, também é comum a estratégia do aproveitamento de personagens e enredos consagrados nos mais diferentes meios de comunicação de massa como cinema, desenhos animados, séries de TV, quadrinhos etc. para o desenvolvimento de novos títulos, incluindo, no caso do cinema, a mesma trilha sonora e, até, imagens exclusivas para os jogos. Relevante é a atual tendência de caminhar no sentido contrário a essa anterior estratégia. Atualmente, personagens, criados originalmente para os jogos, estão sendo exportados para os mesmos MCM, alcançando um bom êxito comercial, apesar de discutível valor estético, como acontece atualmente com os famosos jogos de luta Street Fighter e Mortal Kombat e as aventuras de Mário Bross, Sonic e Double Dragon, além de muitos produtos infantis estampados com as figuras desses personagens.

É coerente concluir, diante das comparações feitas entre os modernos jogos e as estruturas tradicionais dos contos populares, que as empresas multinacionais de entretenimento parecem apenas desenvolver características superficiais próprias sobre uma sólida base estrutural, reconhecida com sucesso por qualquer país consumidor de sua tecnologia.

Dessa maneira, os contos populares sofrem uma pasteurização nas diferentes características regionais presentes na sua forma original, substituindo os folclóricos personagens por novas figuras e mundos artificiais gerados exclusivamente para o computador. A eficácia dessa postura é constatada pela dimensão de popularidade desses jogos, revelada pela atual influência nos outros meios de comunicação. Considerando a recente possibilidade de conexão dos aparelhos com a rede Internet, continuar ignorando o potencial dos jogos eletrônicos passa a ser uma ingenuidade.

\section{O VIDEOGAME E A ESCOLA}

Como foi concluído pela pesquisa promovida pelo Projeto Integrado A circulação de textos na escola, raramente o discurso pedagógico institucional estabelece algum tipo de articulação com as diferentes linguagens, próprias do amplo universo de conhecimento dos alunos ${ }^{7}$. No caso específico do videogame, essa relação é praticamente nula, apesar do relevante número de alunos que o jogam regularmente. Assim, pode-se afirmar, sem margem de erro, que o discurso es-

7. Ver: CITELLI, Adilson Odair. (coord.) Escola e meios de massa. In: Ensinar e aprender com textos não-escolares. São Paulo: Cortez, v, 3, 1997. (Série Aprender e ensinar com textos). 
colar encontra nos jogos eletrônicos um forte concorrente e que deve, portanto, merecer maior atenção por parte dos educadores.

Os avançados recursos visuais e sonoros presentes no videogame, aliados à possibilidade de interação dos jogadores com o universo construído pela máquina, dão aos jogos grande poder de sedução, levando os alunos a dedicar um tempo enorme na tentativa de atingir os objetivos do jogo, pois, na maioria dos casos, não existe nenhum tipo de recurso que permita uma interrupção da atividade para uma retomada futura. Para melhor ilustrar a demanda de tempo exigida, basta mencionar que foram necessárias 14 horas ininterruptas para a conclusão total do jogo Space Ace, descrito nesse artigo. Dificilmente um aluno se colocaria à disposição por tanto tempo em um trabalho escolar, nem é esse o objetivo, mas seria desejável atraí-lo por algum tempo e com tamanho interesse por assuntos ligados ao universo pedagógico.

Essa ocupação do tempo, aliado ao problema dos jogos pasteurizados, leva as crianças a uma demasiada exposição a valores artificiais, difundidos com a mesma intensidade em todas as culturas. Esse aspecto

Resumo: Os videogames obedecem à estrutura morfológica dos contos populares, conforme a propôs V. I. Propp. O antigo e o novo se diferenciam, no entanto, não só pela base tecnológica como também pela pausterização, com a exclusão de características regionais e peculiares às diferentes culturas. Mesmo assim, a escola não pode se furtar à linguagem dos videogames, nem menosprezar a influência que eles exercem no universo discursivo dos alunos.

Palavras-chave: videogame, contos populares, escola, morfologia do conto torna-se extremamente problemático, à medida que se excluem outras possibilidades de absorção cultural, podendo culminar com uma formação limitada no que diz respeito à educação formal ${ }^{8}$.

Cabe à escola, em primeiro lugar, aceitar a realidade da linguagem do videogame e suas influências no universo discursivo dos alunos. A partir desse ponto, seria possível abrir um canal de diálogo com os alunos, deixando o discurso repressivo no passado, promovendo discussões atualizadas que possam identificar, em conjunto, os diversos problemas trazidos por essa nova linguagem e, assim, buscar soluções concretas que permitam à instituição de ensino cumprir seu papel de sistematização e ampliação da formação cultural do seu público.

Afinal, não seria tão difícil convencer um aluno, aficcionado por aventuras eletrônicas, a descobrir um herói como Ulysses e todo o universo mitológico grego, ou ainda, estimulá-lo para a leitura dos contos do Decamerão. Facilitar a descoberta de novos mundos, muitas vezes tão encobertos por um discurso pedagógico distante da realidade cotidiana, é um dos desafios a serem enfrentados pela escola.

Abstract: Today's video games follow the same morphological structure of popular stories, according to the proposed by V. I. Propp. The new and the old are distinguished exclusively on a technological basis and through pasteurization, excluding regional characteristics and those specific to the different cultures. Nevertheless, the school should not ignore the video game language, nor underestimate the influence they have on the discursive repertoire of students.

Key-words: video game, popular stories, school, short story morphology

8. Como o escopo deste artigo é apenas o de mostrar certas recorrências existentes em estruturas narrativas e games, assim como apontar dificuldades na relação do discurso pedagógico com as linguagens institucionalmente não-escolares, não cabe. aqui, análise mais detida sobre possíveis impactos culturais dos jogos eletrônicos na vida dos alunos. Este é um assunto sobre o qual estamos apenas iniciando nossas reflexões e a que pretendemos voltar em outro momento. 